\title{
Student Performance in a Principle of Microeconomics Course under Hybrid and Face-to-Face Delivery
}

\author{
Penny Verhoeven*, Tatiana Rudchenko \\ Kennesaw State University, Georgia, USA \\ *Corresponding author: pverhoev@kennesaw.edu
}

Received October 18, 2013; Revised November 14, 2013; Accepted November 21, 2013

\begin{abstract}
Designing a hybrid course entails the challenge of choosing learning activities for each of the face-toface and online environments--and sequencing and coordinating the activities across the two environments--to promote student attainment of the course's learning objectives. This paper presents a study comparing student performance in an undergraduate Principles of Microeconomics course taught by the same instructor under hybrid (n $=51)$ and face-to-face $(n=24)$ delivery. The percentage of hybrid students completing the course $(71 \%)$ was not significantly different (chi-square $=.61, \mathrm{p}=.433$ ) than that $(79 \%)$ of the face-to-face students. A regression analysis controlling for student GPA indicated that, for students completing the course, the composite test score was, on average, an estimated 4.8 percentage points lower $(\mathrm{p}=.025$, one-tailed) under hybrid delivery than under face-toface delivery. Student GPA had a strong positive ceteris paribus impact ( $\mathrm{p}=.000$, one-tailed) on the composite test score. The finding of a lower level of student learning under hybrid relative to face-to-face delivery is attributed to inattentiveness to pedagogical principles in designing the hybrid course. The study serves as a caution to colleges and universities initiating or expanding their hybrid course offerings in the absence of faculty training or quality control checks. The paper closes with suggestions for further research.
\end{abstract}

Keywords: hybrid course, blended course, face-to-face course, student learning, pedagogy

Cite This Article: Penny Verhoeven, and Tatiana Rudchenko, "Student Performance in a Principle of Microeconomics Course under Hybrid and Face-to-Face Delivery." American Journal of Educational Research 1, no. 10 (2013): 413-418. doi: 10.12691/education-1-10-1.

\section{Introduction}

Though a uniformly-shared definition of a hybrid course (also called a blended course) is lacking, as illustrated by differing definitions offered by the Sloan Consortium [2] and the U.S. Department of Education [17], a hybrid course is generally understood to entail significantly less seat time (time in an on-campus classroom) than a standard face-to-face course, with the reduced seat time replaced by reliance on the Internet. Reliable data as to enrollment levels in hybrid courses are hard to come by, likely due to a number of student record systems lacking a unique course identifier for hybrid courses [3]. However, as early as AY 2006-2007, an estimated $35 \%$ of all U.S. Title IV degree-granting colleges and universities (and 49\% of all such public 4year institutions) were offering at least one hybrid course [17], and a number of colleges and universities have in recent years initiated or expanded their hybrid course offerings $[9,19]$.

The advantages of hybrid courses over face-to-face courses include better accommodating (by reduced time on campus) students with busy work or personal lives and enabling colleges and universities to better utilize limited classroom space, of particular benefit in the current environment of reduced state funding for higher education and pressures to reduce costs $[6,15,16]$. Also, hybrid courses provides students face-to-face interaction with professors and fellow students, thereby affording opportunities for immediate engagement and feedback and a sense of community lacking in fully online courses $[6,16]$. However, it is important to assess whether providing hybrid course offerings in pursuit of their relative advantages occurs at the expense of lower student learning.

This paper presents a study with respect to a Principles of Microeconomics course to complement the literature comparing levels of student learning in undergraduate business courses under hybrid and face-to-face delivery. The study serves as a caution to colleges and universities offering hybrid courses in the absence of faculty training or quality control checks on the hybrid course designs. The paper closes with suggestions for further research.

\section{Literature Review}

Designing a hybrid course entails the challenge of choosing learning activities for each of the face-to-face and online environments and sequencing and coordinating the activities across the two environments--to promote student attainment of the course's learning objectives $[1,4]$. In recognition of that challenge, Brooklyn Community College [19] uses a faculty development program 
"centered in pedagogy" (p. 88) to train and support its faculty in designing hybrid courses. Alberts, Murray, and Stephenson [1] offer as a design guide examples of ways to implement pedagogical principles in an online environment, such as: online quizzes and interactive multimedia software to promote active learning; asynchronous discussion, chats, wikis and blogs to promote collaborative learning; sequencing of online tasks to promote outcomes-based learning; immediate feedback on online quizzes or embedded in interactive software to promote feedback to students; and multimedia to accommodate different learning styles. In this section, we review prior studies (identified through a search of the $\mathrm{ABI} / \mathrm{INFORM}$ database) comparing student learning in undergraduate business courses under hybrid and face-toface delivery, with a special emphasis on how the online environment was (or was not) leveraged to promote student learning under hybrid delivery. (Two studies with respect to introductory statistics are included as a number of business schools have a business core course in introductory statistics.).

\subsection{Principles of Managerial Accounting Course}

The study by Keller et al [10] strongly suggests that mirroring the curriculum and pedagogy of a face-to-face course in a hybrid course can readily lead to similar levels of learning across the two delivery modes. The authors compared the performance of students in two sections of a Principles of Managerial Accounting course, one under hybrid delivery and the other under face-to-face delivery (with respective initial enrollments of 110 and 182 students), with "intentionally minimized curriculum and pedagogy differences" between the two sections (p. 152). The total in-class time of the hybrid students was $50 \%$ that of the face-to-face students. The two sections had the same instructor, mid-term and final exam, online practice quizzes, once-a-week in class lectures, and advanced problems for once-a-week student team work. The team work of the face-to-face students was conducted in class and immediately followed by a professor-led discussion of their answers; the team work of the hybrid students was conducted online with a set due date and with the professor posting the answers online the following day.

Through leveraging the online environment of the hybrid students to promote collaborative learning, provide timely feedback, and keep the students on a steady learning pace, the hybrid students were afforded similar pedagogical support (in addition to the similar curriculum) as were the face-to-face students. The authors' findings are thereby not surprising: In addition to finding no significant difference in the withdrawal rates of $15.4 \%$ and $10.4 \%$ in the respective hybrid and face-to-face sections, the authors found--controlling in a regression (with $\mathrm{n}=$ 163) for grade in the one-hour prerequisite accounting course, SAT score, age, gender, and whether or not the student was a transfer student--no significant difference in the mean course grade under hybrid and face-to-face delivery.

\subsection{Principles of Marketing Course}

Priluck [13] compared the performance, satisfaction, and perceived levels of learning of the students in a hybrid section $(n=27)$ of a Principles of Marketing course to those of the students in a face-to-face section $(n=34)$ of the course, with both sections having the same instructor, covering the same basic material, and having the same comprehensive group project and final exam. The seven in-class sessions for the hybrid section (half the number of in-class sessions for the face-to-face section) "were similar to the traditional class" (p. 166). The hybrid students were afforded active and collaborative learning opportunities in the online environment through online individual assignments related to text readings and four online team assignments to write papers on, respectively, the marketing environment, global consumer behavior, research on a demographic project, and packaging; the corresponding curriculum was addressed for the face-toface students in class through a combination of lecture, inclass discussion, and some in-class team work. Whereas the course grade for the hybrid students was based on their four group papers, two tests, the final exam, and the comprehensive group project, the course grade for the face-to-face students was based on one individual paper, two different tests, the (common) final exam, and the (common) comprehensive group project.

A t-test yielded no significant difference in the mean final exam scores of the hybrid students (80 points) and face-to-face students (83). However, given that the hybrid students were on average five years older than the face-toface students and had a significantly lower mean level of perceived learning than the face-to-face students for multiple topics that were addressed in the online environment, had the comparison of final exam scores controlled for student ability, the finding may very well have been one of lower levels of student learning under hybrid than face-to-face delivery. In addition, the mean level of satisfaction of the hybrid students with the course (2.6 on a 5-ponit scale) was significantly lower than that (4.2) of the face-to-face students. In discussing the implications of the study, Priluck suggested that "Class time [for the hybrid students] should be spent integrating the concepts using cases and examples that apply the material that has already been learned in the online portion of the course” (p. 171), in essence, proposing a modified hybrid course design in response to student perceptions

\subsection{Accounting Information Systems Course}

Dowling, Godfrey, and Gyles [8] compared student performance in a (second) course in Accounting Information Systems under hybrid and face-to-face delivery, restricting the analysis to students on two campuses over two consecutive years who had completed the mid-term assessment and final exam of the course and had as well completed the three prerequisite courses. The resulting total of 95 students receiving hybrid delivery and 111 students receiving face-to-face delivery were taught by the same instructor and given comparable mid-term assessments and final exams. Under face-to-face delivery, 24 hours of lecture and 12 hours of workshops "in which the unit's practical components were covered” took place in class (p. 376). Under hybrid delivery, lectures were delivered online in the form of narrated PowerPoint slides and 24 hours of class time were employed to incorporate "the practical exercise component of the course" as well as "examine the set material in depth" (p. 377).Most 
hybrid courses entail one-half the seat time as face-to-face courses; in this instance, the hybrid course entailed twothirds the seat time as the face-to-face course. The hybrid students had more total in-class time devoted to skill development and discussion and in smaller class sizes (31 to 40) than the face-to-face students (51 and 123). The online environment for the hybrid students was restricted to passive learning, as no quizzes or assignments based on the online lectures were required.

Controlling in OLS regressions for average grade on the three prerequisite courses, gender, campus location, age, and part-time versus full-time student status, hybrid delivery was estimated to result in a $3 \%$ lower $(p=.006)$ mid-term assessment grade, $5 \%$ higher final exam (p $=.000)$ grade, and $2 \%$ higher course grade $(p=.0185)$ than face-to-face delivery. Average grade on the three prerequisite courses had a highly significant $(\mathrm{p}=.000)$ positive ceteris paribus effect on all three measures of student learning.

\subsection{Legal Environment of Business Course}

Dana [6] describes her systematic approach to transforming her face-to-face Legal Environment of Business course into a hybrid course, reporting that her most recently taught 115 face-to-face students and 101 hybrid students had essentially identical mean course grades (on a 4-point scale) of 2.96 and 2.95, respectively,. Though not offered as a formal comparative study, her approach serves as an exemplar of applying pedagogical principles to the design of a hybrid course. Each week's content coverage was held the same for the face-to-face and hybrid versions. The hybrid course involved one inclass lecture and one online student task or assignment per week, with the lectures designed to "ensure that every minute of lecture was instrumental in adding value to the course," the online work (e.g., a guided search for information on the web, a quiz on an assigned chapter reading, a group debate on a case) designed to incorporate "active learning course requirements," and each individual weekly lecture or online activity tied to particular learning objectives (p. 169).

\subsection{Introductory Statistics Course (at Carnegie Mellon)}

Lovett, Meyer, and Thille [11] compared student learning in an Introductory Statistics course under hybrid and face-to-face delivery. The hybrid version of the course was based on an existing fully online course that is part of Carnegie Mellon's Open Learning Initiative (OLI) to make highly interactive online courses widely available, with each OLI course developed by a team of experts in pedagogy, course content, human-computer interaction, and software engineering. Students who had originally enrolled in face-to-face sections of the course in the Spring of 2007 and who had volunteered to take the course under accelerated (over an 8-week time frame) hybrid delivery were randomly assigned to take the course under accelerated hybrid delivery $(\mathrm{n}=22)$ or face-to-face (over a 15-week time frame) delivery $(n=42)$.

Hybrid delivery entailed use of the OLI Statistics course in addition to half the number of 50-minute faceto-face classes afforded under face-to-face delivery. The pedagogy embedded in the OLI Statistics course included relating any given topic to a displayed hierarchy of course topics to continually "reiterate to students how the pieces of the course fit together" (p. 3), "interspersing frequent practice opportunities within the expository text” (p. 4), and providing students immediate feedback during those practice opportunities. The instructor of the hybrid class selected for each class session "material...designed to target students' difficulties based on the OLI system's automatically generated reports on students' performance in the course" (p. 8). No mention was made of the pedagogy employed by the instructors of the face-to-face students.

Apart from the one hybrid student and two face-to-face students who did not complete the course (indicating similar course completion rates of 21/22 and 40/42), each of the hybrid and face-to-face students were given, in class, four tests (three midterms and a final) of comparable (across the students) content and level of difficulty. For each of the four tests, there was no significant difference in the mean test score under hybrid and face-to-face delivery. Additional analyses conducted by the authors indicated that, overall, the hybrid students spent half the total time learning the material than did the face-to-face students and as well--and unlike the face-to-face students-experienced a significant $(p<.001)$ pre-test to post-test gain in learning (an estimated 18 percentage points on average) on the Comprehensive Assessment of Outcomes in a first Statistics course (CAOS) test on statistics [7].

\subsection{Introductory Statistics Course (at six public universities)}

The OLI Statistics course played a central role in the study described by Bowen et al [5] that involved 605 students from six public universities who agreed to participate in an experiment in which the students were randomly assigned to take Introductory Statistics at their home university in either hybrid or face-to-face mode. In the study, the hybrid course sections relied on the OLI Statistics course for the online component. The study found very strong evidence--both with and without controlling for student characteristics such as GPA, gender, age, family income, and primary language spoken at home-that hybrid and face-to-delivery resulted in essentially the same pass rates, mean scores on a set of final exam questions held the same under both delivery modes at the same university, and mean scores on the aforementioned CAOS test of statistical literacy [7] taken at the end of the course. With the hybrid students reporting spending .3 hours more per week outside of class on the course than the face-to-face students, the authors estimated that the hybrid students (given their reduced in-class time relative to the face-to-face students) achieved the same learning outcomes as the face-to-face students while spending $25 \%$ less total time on the course.

\subsection{Sports Economics Course}

Vogel [18] compared the performance of students taking Sports Economics under face-to-face delivery (in any one of three sections) and hybrid delivery (in a single section), with the total in-class time of the hybrid students half that of the face-to-face students. The hybrid and faceto-face students had in common: the topic coverage; textbook and readings; requirements to write a mid-term 
essay and a final essay in class; written assignments posted online; the requirement to submit a journal; and online access to the PowerPoint slides underlying the inclass lectures. Class sessions for the face-to-face students comprised "a mix of class discussion and lecture with some occasional group exercises” (p. 81) and class sessions for the hybrid students comprised a mix of class discussion and lecture, with additional mini-lectures posted online for the hybrid students. The online environment for the hybrid students was devoid of active or collaborative learning opportunities. In addition, unlike for the face-to-face students, the in-class time for the hybrid students did not incorporate any group exercises. Based on a Tobit regression controlling for attendance, Vogel estimated “...if a student took the course in the hybrid format, their grade was likely to be 4 percent lower than had the course been taken in the traditional format" (p. 83). No control for student ability was applied.

In the next section, a new study is offered to complement the literature comparing student learning in undergraduate business courses under hybrid and face-toface delivery.

\section{New Study}

\subsection{Setting}

The study was conducted at a large public university, the majority of whose students work and commute to campus. The university's business college offered its first hybrid course in 2011 and seeks to expand its hybrid course offerings. The college offered its first online course over a decade earlier and presently offers three online undergraduate business degree programs and--in partnership with sister universities--a fully online MBA. Whereas every online course must pass a quality control check based on online learning standards [14], no quality control check is as yet exercised with respect to hybrid courses. Faculty willing or wanting to develop and teach a hybrid course in their discipline area are welcome to do so. Every hybrid course offered at the university entails students meeting in class for half the time as a face-to-face course. The study focuses on the undergraduate Principles of Microeconomics course, a lower-division business core course with a college algebra (or higher) math course as a prerequisite.

\subsection{Subjects and Course Design}

The subjects were the 51 students enrolled in a hybrid section of Principles of Microeconomics and the 24 students enrolled in a face-to-face section of the course, with both sections taught the same sixteen-week term by the same professor, and having the identical textbook, topic coverage, four proctored (in class) multiple-choice quizzes, proctored (in class) multiple-choice final exam, and optional non-proctored bonus exercises. The quizzes and the final exam were graded on the traditional 0 to 100 point scale, and the course grade was based on the average of the four highest grades on the quizzes and final exam, augmented by up to ten points for the bonus exercises. The hybrid section met for 1.25 hours once a week and the face-to-face section for 2.75 hours (with a fifteen-minute break midway) once a week.
In the hybrid section, class time was devoted exclusively to PowerPoint-based lectures delivered by the professor (with questions raised by the students during the lectures addressed by the professor). In the face-to-face section, the same amount of class time was devoted to the same PowerPoint-based lectures delivered by the professor (again, with questions raised by the students during the lectures addressed by the professor), and the additional post-break class time was devoted to working on practice problems in an interactive manner, with students initially working on the problems individually or in groups at their seats and the professor going over the problems on the board, soliciting input from students.

Each section had a Desire 2 Learn course management system account on which was posted the syllabus, the PowerPoint slides underlying all the lectures delivered by the professor, and practice quizzes and a practice final exam with answer keys (merely specifying the correct choice of answers for each multiple-choice question) provided for all but practice quiz three. Students in both sections had the opportunity to attend weekly study sessions (not held on the same day as the class) on the course material led by economics faculty other than the professor. Students in both sections were as well given a link [11] to a series of lectures on microeconomics principles provided by the Khan Academy, with the series mapped to particular chapters in the textbook.

\subsection{Research Hypothesis}

Given the provision of weekly interactive in-class practice on problems for the face-to-face students, with no compensatory or additional learning activities afforded the hybrid students, we adopted the following research hypothesis:

Research Hypothesis: The level of student learning in Principles of Microeconomics is lower under hybrid delivery than under face-to-face delivery.

Given that the course grade was based predominantly on the average of the four highest grades on the four quizzes and final exam, we used that average--hereafter termed composite test score--as the measure of student learning. Only students completing the course--defined as taking at least four of the quizzes and final exam--were included in the analysis. The course completion rates of $71 \%$ for the hybrid students and $79 \%$ for the face-to-face students were not significantly different (chi-square $=.61$, $\mathrm{p}=.433)$.

\subsection{Results and Discussion}

Table 1 provides descriptive statistics on the ages, cumulative GPAs at the beginning of the study term, and composite test scores of the hybrid and face-to-face students completing the course.

Table 1. Descriptive Statistics on Hybrid and Face-to-face Students Completing Course

\begin{tabular}{|c|c|c|}
\hline Measure & Hybrid & Face-to-face \\
\hline Number of students & 36 & 19 \\
\hline Mean age & $22.5(7.0)$ & $23.3(6.1)$ \\
\hline Mean GPA & $3.02(.51)$ & $2.68(.63)$ \\
\hline Mean composite test score & $72.7(11.0)$ & $73.5(9.2)$ \\
\hline
\end{tabular}

Note 1: Standard deviations in parentheses

Note 2: GPA = cumulative GPA at beginning of term

Note 3: Composite test score $=$ average of four highest grades on four quizzes and final exam 
The research hypothesis was tested by an OLS regression of composite test score on GPA and mode of course delivery (Hybrid $=1$ if hybrid delivery, 0 if faceto-face delivery). The results in Table 2 indicate that, controlling for GPA, the mean composite test score was significantly lower--an estimated 4.8 percentage points lower--under hybrid delivery than under face-to-face delivery, and that GPA had a strong positive strong positive ceteris paribus impact on the composite test score.

Table 2. OLS Regression Results with Composite Test Score as Dependent Variable $(n=55)$

\begin{tabular}{|c|c|c|c|c|}
\hline Variable & Coefficient & Std. Error & t-Statistic & $\mathrm{p}$-value \\
\hline Intercept & 41.3101 & 5.6828 & 7.2693 & .0000 \\
\hline GPA & 11.9988 & 2.0050 & 5.9845 & .0000 \\
\hline Hybrid & -4.7734 & 2.3884 & -1.9986 & .0509 \\
\hline Adjusted R & .386 & & & \\
\hline F-statistic & $17.95(\mathrm{p}=.000)$ & & & \\
\hline
\end{tabular}

Note 1: Hybrid = 1 if hybrid delivery, 0 if face-to-face delivery

Note 2: p-values are two-tailed

The negative impact of hybrid relative to face-to-face delivery on student learning can be explained in large part by the hybrid students having no required learning activities to compensate them for the ongoing in-class practice working analytical problems afforded the face-toface students. Examples of those analytical problems include deriving mathematically and/or identifying based on graphical displays: equilibrium prices and quantities; the price elasticity of demand and of supply; consumer and producer surpluses; producers' average total cost curves; the impact of taxes on total surplus; and profitmaximizing quantities and associated profits for competitive firms and monopolies. Practice on such problems, particularly in the interactive manner afforded the face-to-face students, would be expected to promote student attainment of the learning objectives (related to skills as well as terms and concepts) that are central to the course and that the quizzes and final exam are expressly designed to assess.

Though the hybrid students could choose to attend additional study sessions offered on campus on a different day than the class, the very advantages (reduced trips to or time on campus, greater scheduling flexibility) of hybrid over face-to-face delivery would be obviated by hybrid students attending those study sessions. Consultation with the faculty providing the study sessions revealed that only a handful of the students enrolled in the fifteen sections of Principles of Microeconomics offered during the study term attended any given study session (not surprising given the predominantly working and commuting students attending the university); thus, few to none of the hybrid students exercised the option to attend additional study sessions.

The use of the online environment for the hybrid students was restricted to the provision of non-interactive content (PowerPoint slides, Khan Academy lectures, and multiple-choice questions in the form of practice quizzes and a final exam with the correct answer choices simply specified). No online learning activities were required of the hybrid students. The face-to-face environment for the hybrid students was restricted to receiving lectures with the opportunity to raise questions during the lectures. The passive learning in the face-to-face environment was not supplemented by active or collaborative learning (or other forms of student engagement in learning) in the online environment. In summary, then, the poor hybrid course design - which disadvantaged the hybrid relative to the face-to-face students - can well explain the lower level of student learning of the hybrid students.

Limitations of the study include the small sample sizes (thus a large standard error on the estimated effect of hybrid delivery) and the noise inherent in the calculation of the composite test score.

\section{Conclusion}

The study presented in this paper comparing student learning in a Principles of Microeconomics course under hybrid and face-to-face delivery found a lower level of student learning under hybrid delivery that could be attributed to inattentiveness to pedagogical principles in designing the hybrid course. The major implication of the study is that, in the absence of any faculty training in developing a hybrid course or any quality control checks on hybrid course offerings, institutions' hybrid course offerings may be detrimental to student learning. Pursuant to promoting effective hybrid course design, we recommend further research to address the following questions: Do colleges and universities with quality control checks on their hybrid course offerings experience better student outcomes than colleges and universities without quality control checks? What is the effect on student learning in hybrid courses of the frequency (e.g., weekly, biweekly, monthly) of online deliverables (e.g., assignments, quizzes) required of hybrid students? What impact would providing faculty a checklist/description of pedagogical principles and examples of ways to implement those principles in an online environment have on their hybrid design choices? What impact would providing faculty exemplars of hybrid course design have on their hybrid design choices? Do hybrid courses developed by disciplinary teams of faculty result in better student outcomes than hybrid courses developed by individual faculty?

\section{List of Abbreviations}

CAOS: Comprehensive Assessment of Outcomes in a first Statistics course

OLI: Open Learning Initiative

\section{References}

[1] Alberts, P.P., Murray, L.A., and Stephenson, J.E. (2010). Eight Educational Considerations for Hybrid Learning. In R. Kwan, J. Fong, and F.L. Wang (Ed.), Handbook of Research on Hybrid Learning Models: Advanced Tools, Technologies, and Applications (pp. 185-202). Information Science Reference: Hershey, PA. Available: EBSCO e-book.

[2] Allen, I.E., and Seaman, J. (2013). Changing Course: Ten Years of Tracking Online Education in the United States. Sloan Consortium: USA.http://www.onlinelearningsurvey.com/reports/changingcours e.pdf.

[3] Allen, I.E., Seaman, J., and Garrett, R. (2007). Blending in: The Extent and Promise of Blended Education in the United States.Sloan Consortium: USA.

http://sloanconsortium.org/publications/survey/blended06.

[4] Boora, R., Church, J., Madill, H., Brown, W., and Chykerda, M. (2010). Ramping up to Hybrid Teaching and Learning.In R. Kwan, J. Fong, and F.L. Wang (Ed.), Handbook of Research on Hybrid 
Learning Models: Advanced Tools, Technologies, and Applications (pp. 406-423). Information Science Reference: Hershey, PA. Available: EBSCO e-book.

[5] Bowen, W.G., Chingos, M.M., Lack, K.A., and Nygren, T.I. (May 22, 2012). Interactive Learning Online at Public Universities: Evidence from Randomized Trials. Ithaka: USA.

http://www.sr.ithaka.org/research-publications/interactivelearning-online-public-universities-evidence-randomized-trials.

[6] Dana, S.R. (2013). "The Emergence of the Hybrid Delivery Approach: Utilization of a Six Step Instructional Model for Business Law Curriculum,” Journal of Legal Studies in Business 18:159-190.

[7] delMas, R., Ooms, A., Garfield, J., and Chance, B. (2006) “Assessing Students' Statistical Reasoning.”In Proceedings of the Seventh International Conference on the Teaching of Statistics. Salvador, Brazil.

[8] Dowling, C., Godfrey, J.M., and Gyles, N. (2003). "Do hybrid flexible delivery teaching methods improve accounting students' learning outcomes?"Accounting Education12(4):373-391.

[9] Instructional Technology Council (May 2011). 2010 Distance Education Survey Results. Instructional Technology Council: Washington, D.C.

http://www.itcnetwork.org/attachments/article/66/ITCSurveyResul tsMay2011Final.pdf.

[10] Keller, J.H., Hassell, J M., Webber, S.A., and Johnson, J.N. (2009). "A comparison of academic performance in traditional and hybrid sections of introductory managerial accounting." Journal of Accounting Education 27:147-154.

[11] Khan Academy. Lectures on Microeconomics Principles. http://www.khanacademy.org/finance-economics/microeconomics.
[12] Lovett, M., Meyer, O., and Thille, C. (May 2008). "The Open Learning Initiative: Measuring the Effectiveness of the OLI Statistics Course in Accelerating Student Learning.”Journal of Interactive Media in Education. http://www-jime.open.ac.uk/.

[13] Priluck, R. (2004). "Web-Assisted Courses for Business Education: An Examination of Two Sections of Principles of Marketing." Journal of Marketing Education26(2): 161-173.

[14] Quality Matters Program (2011). Quality Matters Rubric Standards 2011-2013 edition with Assigned Point Values. Maryland Online, Inc. http://www.qualitymatters.org/rubric.

[15] Rubin, B. (March 2013). "University Business Models and Online Practices: A Third Way.” Online Journal of Distance Learning Administration 15(1):17 pages. University of West Georgia. http://www.westga.edu/ distance/ojdla/spring161/rubin.pdf.

[16] Terry, N. (2007). "Assessing Instruction Modes for Master of Business (MBA) Courses.”Journal of Education for Business 82(4): 220-225.

[17] U.S. Department of Education (December 2008). Distance Education at Degree-Granting Postsecondary Institutions: 20062007. Washington, D.C. http://nces.ed.gov/pubsearch/pubsinfo.asp?pubid=2009044

[18] Vogel, R. (2011). "Switching Economics Courses from Online Back to the Classroom: Student Performance and Outcomes." International Journal of Business and Social Science2 (22):79-84.

[19] Wach, H., Broughton, L., and Powers, S. (Feb 2011). "Blending in the Bronx: The Dimensions of Hybrid Course Development at Bronx Community College,” Journal of Asynchronous Learning Networks 15(1):87-94. 